EESTI NSV TEADUSTE AKADEEMIA TOIMETISED. 20. KÖIDE

KEEMIA * GEOLOOGIA. 1971, NR. 4

ИЗВЕСТИЯ АҚАДЕМИИ НАУК ЭСТОНСКОИ ССР. ТОМ 20

химия * ГЕология. 1971, № 4

Н. ЗЛОБИН

УдК $547,313-543,54$

\title{
ДЕГИДРИРОВАНИЕ Н-ОКТАНА В ПАРОВОЙ ФАЗЕ НА ПЛАТИНОВЫХ КАТАЛИЗАТОРАХ
}

Процесс дегидрирования нормальных парафинов в парогазовой фазе изучен детально, вплоть до промышленных условий, применительно к низшим членам гомологического ряда. В настоящее время возрастает интерес к избирательному дегидрированию $н$-парафинов с восемью-шестнадцатью атомами углерода в молекуле до соответствующих моноолефинов. Настоящее сообщение содержит результаты первого этапа исследования в этом аспекте, проведенного с $н$-октаном как модельным веществом при использовании микрореакционной газовой хроматографин, широко применяемой в последние годы в аналогичных целях $\left[{ }^{1-5}\right]$.

Известен ряд работ по дегидрированию в паровой фазе парафинов $\mathrm{C}_{5}-\mathrm{C}_{9}$ на алюмохромокалиевых и алюмохромовых катализаторах $\left[{ }^{6-10}\right]$ и ряда $\boldsymbol{H}$-гептан-гексадекан на цинкхромовых катализаторах, нанесенных на окись цинка $\left[{ }^{11-13}\right]$. В последние годы ряд отечественных исследований $\left[{ }^{14-15}\right]$ и зарубежных патентов $\left[{ }^{16-20}\right]$ указывает на существенные достоинства металлов VIII группы как катализаторов парофазного дегидрирования. Особенно эффективным представляется платиновый катализатор, нанесенный на окись алюминия, который избран нами для проведения псследования на первом этапе после тщательного анализа данных литературы.

\section{Методика исследования}

Эксперимент проведен в импульсном режиме при величине разовой дозы исходного углеводорода $1-1,5$ мг. Микрореактор представляет собой трубку из нержавеющей стали длиной 25 мм и диаметром в свету 4 мм, помещенную в разъемную трубчатую печь - термостат с регулированием температуры в пределах $300-460{ }^{\circ} \mathrm{C}$. Колонка газового хрома . тографа УХ-1, в которую поступают продукты реакции, длиной 6 м заполнена полиэтиленгликолем 4000 на хромосорбе $P$. В ней поддерживается температура $120-125^{\circ}$, расход газа-носителя гелия составляет $50 \mathrm{мл/мин.} \mathrm{Обработка} \mathrm{хроматограмм} \mathrm{произведена} \mathrm{методом} \mathrm{внутренней}$ нормализации.

Катализатор изготовлен путем нанесения платины на гранулы окиси алюминия $(0,2-0,4$ мм $)$ по методике из [21]. Содержание платнны в готовом катализаторе варьируется: от 2,5 до 1,$0 ; 0,5 ; 0,25$ вес. $\%$. После каждой серии экспериментов была произведена регенерация катализатора продувкой воздухом, а затем - водородом при $300^{\circ}$. Работа его после этой операции стабилизируется (элиминируется сильное деструктирующее действие) лишь после нескольких импульсов [15], число которых определяется количеством катализатора. Учет этого обстоятельства, наряду с точностью дозировки реагента в импульсе, определяет стабильность и сопоставимость результатов экспериментов. 


\section{Результаты исследования и их обсуждение}

В соответствии с характеристикой катализатора (долей нанесенной платины) эксперименты распределены на четыре группы. В каждой из них варьируются - температура в пределах $300-460^{\circ}$ и длина слоя катализатора от 6 до 3,2 и 1 cм (объем слоя соответственно 0,75, 0,37, 0,25 и $\left.0,12 \mathrm{~cm}^{3}\right)$. Второй показатель косвенно характеризует длительность контакта реакционной смеси с катализатором.

Эффективность процесса дегидрирования оценивалась нами, как это обычно принято, по двум показателям. Первый - величина выхода целевого продукта реакции (олефинов) от исходного углеводорода; второй - селективность процесса, которая выражается выходом октенов в расчете на прореагировавший $н$-октан.

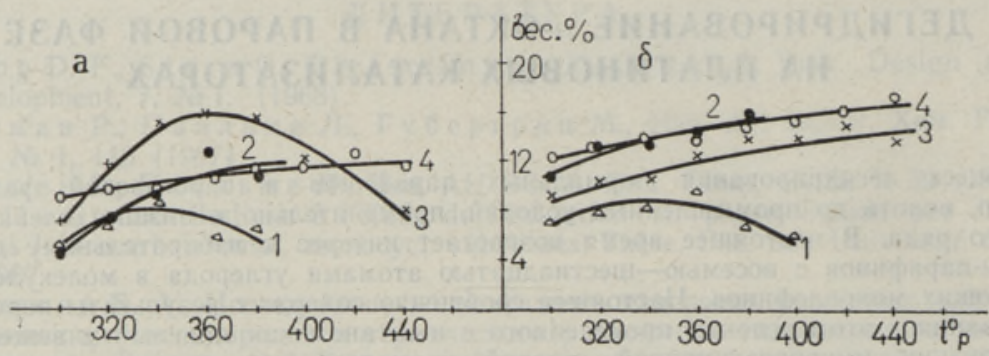

Рис. 1. Выход октенов в процессе дегидрирования $\boldsymbol{H}$-октана при повышенном содержании платины в катализаторе.

$a$ - содержание платины 2,5 вес, $\%, \sigma-$ содержание платины 1,0 вес. \%. 1 - длина слоя $(L)=6 \mathrm{cM} ; 2 \rightarrow L=3 \mathrm{cM} ; 3-L=2 \mathrm{cM}, 4-L=1 \mathrm{cM}$.

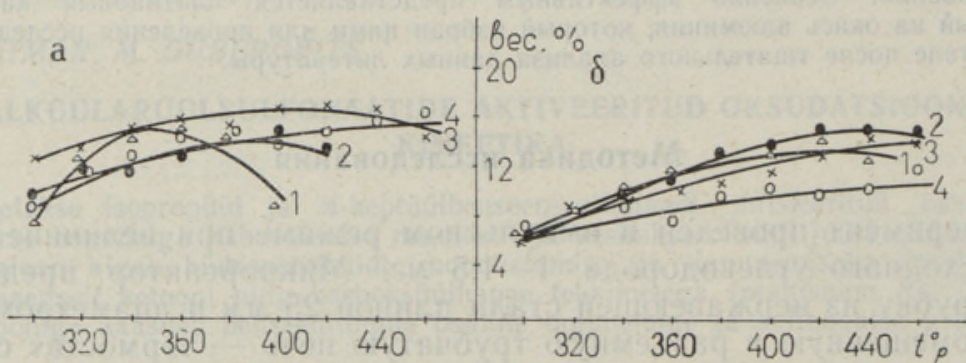

Рис. 2. Выход октенов от исходного углеводорода при пониженном содержании активного компонента в катализаторе.

$a$ - содержание платины 0,5 вес. \%, 6- содержание платины 0,25 вес. \%. Обозначенне кривых см. на рис. 1.

На рис. 1 и 2 приведены кривые, характеризующие выход суммы олефинов от исходного $н$-октана как функцию температуры и варьируемой длины слоя $L$, для катализаторов с различным содержанием платины. Специфичным во всех случаях является наличие максимума в кривых типа 1 , т. е. для наибольшей величины $L=6$ см. Этот максимум сме щается в сторону более высокой температуры по мере убывания количества платины в составе катализатора. Так, для группы $1(2,5 \% \mathrm{Pt})$ максимум выхода октенов достигает $8 \%$ и соответствует температуре около $340^{\circ}$ (рис. $\left.1 a\right)$. В группе $4(0,25 \%$ Pt) наибольший выход (около $12 \%$ ) зафиксирован при более высокой температуре - около $400-420^{\circ}$ (см. рис. 2 б). 
Уменьшение длины слоя $L$ в пределах каждой группы, т. е. при неизменном составе катализатора, также влечет за собой сдвиг максимума кривых для выхода целевого продукта в область повышенной температуры. Это явление, которое наглядно демонстрируют кривые на рис. $2 a$, представляется естественным и не требует пояснений. Точка перегиба и последующий спад наблюдаются не для всех кривых выхода октенов (рис. 1,2$)$, поскольку не во всех случаях достигается достаточно высокая температура.

Закономерное уменьшение выхода октенов с повышением температуры начиная с некоторого критического ее значения для данной величины $L$ в пределах каждой группы связано с достижением своеобразного порога интенсификации побочных реакций - деструкции, циклизации и ароматизации исходного и дегидрированного октана.

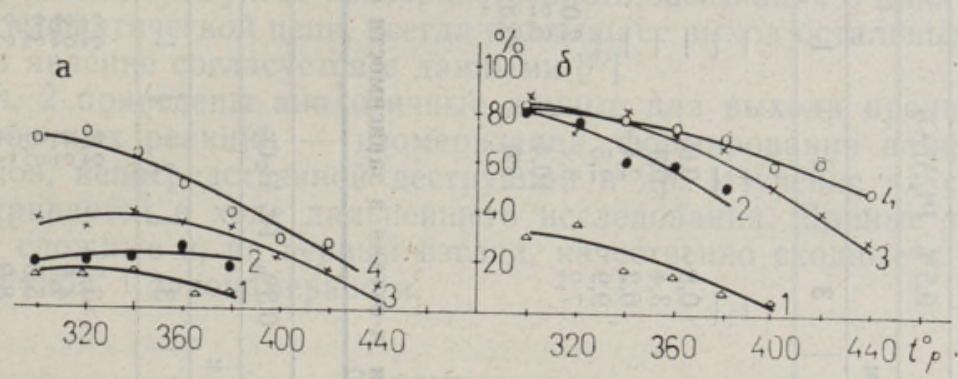

рис. 3. Селективность процесса дегидрирования при повышенном содержании платины в катализаторе.

$a$ - содержание платины 2,5 вес. \%, б - содержание платины 1,0 вес. \%. Обозначение кривых см. на рис. 1 .

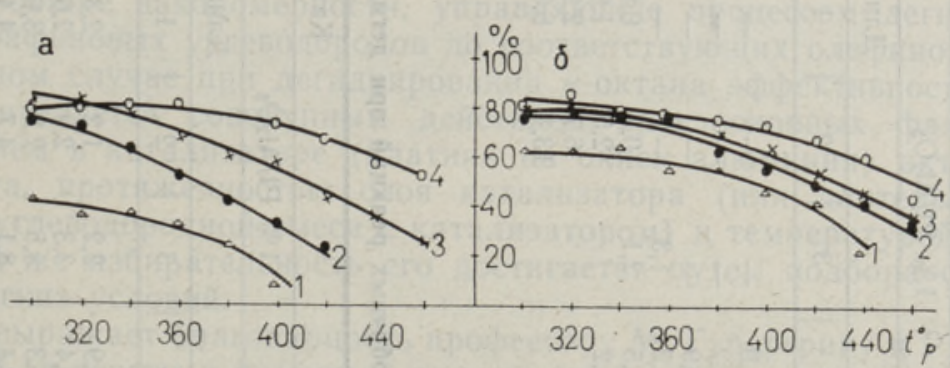

Рис. 4. Селективность процесса дегидрирования при пониженном содержании активного вещества в катализаторе.

$a$ - содержание платины 0,5 вес. \%, б- содержание платины 0,25 вес. \%. Обозначение крнвых см. на рнс. 1.

На рис. 3 и 4 приведены кривые изменения селекгивности процесса как функции температуры и длины слоя в тех же четырех группах опытов. Во всех случаях селективность снижается с ростом температуры в реакторе. Она оказывается более высокой при использовании катали затора с наименьшим содержанием платины и слоя минимальной протяженности, т. е. при ведении процесса в наиболее мягких условиях. Сопоставление кривых на рис. 1, 2 с кривыми на рис. 3,4 показывает, что для катализаторов с содержанием дегидрирующего агента 0,25-0,5\% максимальному выходу октенов $14-16 \%$ отвечает селективность $40-50 \%$. Использование катализатора с повышенным содержанием платины в более значительной мере стимулирует протекание побочных и вторичных реакций и селективность, соответствующая максимальному выходу октенов, в этом случае значительно ниже. 


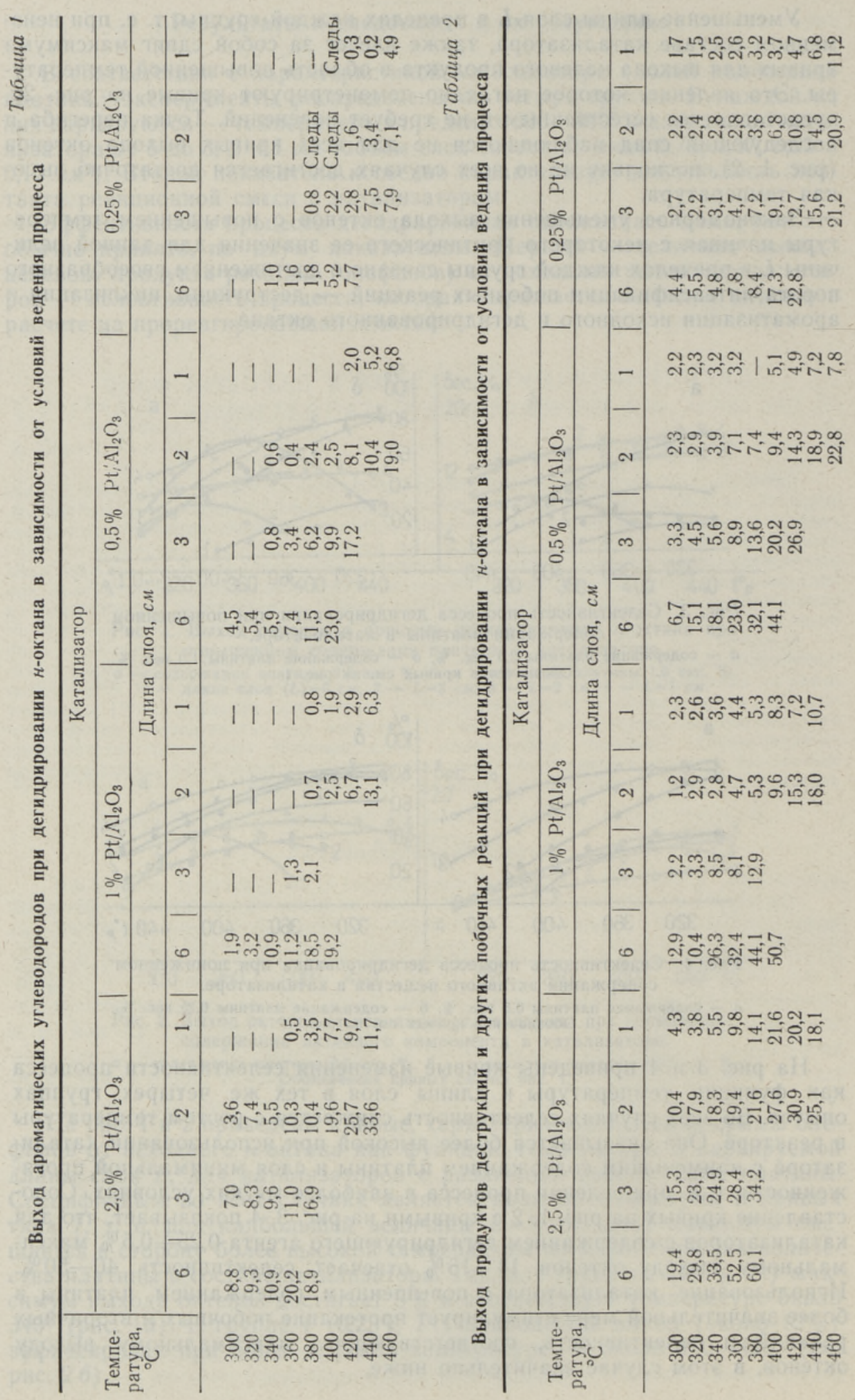


Из продуктов указанных побочных реакций представляют интерес прежде всего ароматические углеводороды - продукты наиболее глубоких (в данных условиях) термокаталитических превращений. Выход их как функция температуры при различной длине слоя катализатора для всєх групп опытов показан в табл. 1.

Наиболее значительная ароматизация, как и следует из ранее сказанного, наблюдается при использовании катализаторов с повышенным $(2,5 \%)$ содержанием платины, даже при сравнительно невысокой температуре. В наименьшей степени реакционная смесь ароматизируется при самом малом содержании активного компонента $(0,25 \%)$ в катализаторе. Уменьшение протяженности слоя, естественно, снижает выход ароматиче ских углеводородов. В составе их идентифицированы бензол, его монометил и этил-производные, $о-, \mu$ и $n$-ксилолы. При этом выход этилбензола и $о$-ксилола, продуктов непосредственного замыкания в цикл дегидрируемой алифатической цепи, всегда превышает выход остальных гомологов. Это явление согласуется с данными [22].

В табл. 2 приведены аналогичные данные для выхода прочих продуктов побочных реакций - изомеризации, формирования алифатических циклов, непосредственной деструкции и др. Изучение их состава предусматривается в ходе дальнейшего исследования. Данные табл. 2 отражают сложные и, на первый взгляд, качественно сходные с приведенными в табл. 1 закономерности.

\section{Заключение}

Изложенные материалы показывают, что применение микрореакционной газовой хроматографии позволяет наиболее простым образом выяснить общие закономерности, управляющие процессом дегидрирования парафиновых углеводородов до соответствующих олефинов.

В данном случае при дегидрировании $\mu$-октана эффективность процесса определяется совокупным действием трех основных факторов: содержанием в катализаторе (платина на окиси алюминия) активного компонента, протяженностью слоя катализатора (или длительностью контакта углеводородной смеси с катализатором) и температурой. Максимальная же избирательность его достигается путем подбора относительно мягких условий.

Автор выражает благодарность профессору М. Губергрицу и Р. Крас нощековой за советы и помощь в выполнении и оформлении работы.

\section{ЛИТЕРАТУРА}

1. Бе резкин В. Г., Аналитическая реакционная газовая хроматография, М., 1966

2. Р а н г С., Эй з е н О., С а л у с т е С., Изв. АН ЭССР, Хим. Геол., 18, № 1, 17 (1969).

3. Р а н г С., Э й з е н О., Изв. АН ЭССР, Хим. Геол., 18, № 1, 23 (1969).

4. Р а н г С., Эй з ен О., Изв. АН ЭССР, Хим. Геол., 17, № 4, 341 (1968).

5. Ke ule ma n s A. J. M., V o g e H. M., J. Phys. Chem., 63, 476 (1959).

6. Тимофеева Е. А., Шуйкин Н. И., Смирнов В. С., Добрынина Т. Н., Пло тн и ков Ю. Н., Пе тр яев а Г. С., Изв. АН СССР, ОХН, № 7, 893 (1958)

7. Шуйкин Н. И., Тимофеева Е. А., Добрынина Т. Н., Плотников Ю. Н. Пе т р яев а Г. С., Клеймен ов а В. М., Изв. АН СССР, ОХН, № 7, 896
(1958).

8. Тимофеев а Е. А., Ш уйкин Н. И., Плотников Ю. Н., К лейменов а Б. М., Докл. АН СССР, 125, № 6, 1272 (1959).

9. Тимофеева Е. А., Шуйкин Н.И., Плотников Ю. Н., Клейменова В.М., Докл. АН СССР, 129, № 1, 128 (1959).

10. Шуйкин Н. И., Тим офеев а Е. А., Клейменов а В. М., Изв. АН СССР, $\mathrm{OXH}$, № 4, 653 (1961). 
11. С ергиенко С. Р., Г арбалинский В. А., Медведева В. Д., Петро . в а А. А., Изв. АН ТуркмССР, сер. физ.-техн., химич. и геолог. н., № 1, 30 (1963).

12. Сергиенко С. Р., Медведева В. Д., Гарбалинский В. А., Изв. АН ТуркмССР, сер. физ.-техн., химич. и геолог. н., № 3, 25 (1964).

13. С ергиенко С. Р., М ед ведев а В. Д., П т ров а А. А., Ч и ров а Е. В., Изв. АН ТуркмССР, сер. физ.-техн., химич. и геолог. н., № 5, 61 (1964).

14. Клесмент И., Кр аснощеков а Р., Изв. АН ЭССР, Хим. Геол., 17, № 4, 332 (1969).

15. Ив в но в А., Э й з ен О., Изв. АН ЭССР, Хим. Геол,, 19, № 1, 15 (1970).

16. M y ers J. W., Пат. США 3151180 ; опубл. 29/XI 1964.

17. Kurha r P. J., Пат. США. Кл.260-683,3 (СО7 с, ВО1 ј) № 3448 165; опубл. 3/VI 1969.

18. В 1 о с h H. S., Пат. США. Кл:260-683,3 (CO7 с, ВО1 ј) № 3448 165; опубл. 3/VI 1969.

19. В l о с h H. S., Пат. США. Кл. 260-671 (CO7 c, ВО1 ј) № 3459822 ; опубл. 5/VIII 1969.

20. A bel1 J. B., F a nn in L. W., R oth J. F.. Пат. США. Кл. 260-683, 3 № 3315 007; опубл. 18/IV 1967.

21. Р анг С., Эй зен О., К унин г а с К., Изв. АН ЭССР, Хим. Геол., 17, № 3, 217 (1968).

22. В л ас о в В. Г., Фом и ч е в Ю. В., К а з а н с и й Б. А., Изв. АН СССР, Хим., № 1 , 64 (1970)

Ннститут химии
Академии наук Эстонской ССР

Поступила в редакцию 2/VI 1971

N. $Z L O B I N$

\section{AURUFAASIS NORMAALOKTAANI DEHODREERIMINE PLAATINA- KATALUSAATORITEL}

Esitatakse normaaloktaani hêeliumi voolus katalüsaatoril $\mathrm{Pt} / \mathrm{Al}_{2} \mathrm{O}_{3}$ dehüdreerimise tulemused, kusjuures uurimiseks kasutati mikroreaktsiooni-gaasikromatograafiat.

Samuti tuuakse ära andmed Pt koguse mõju kohta kandjale ning katalüsaatori kihi pikkuste, reaktori temperatuuride, okteenide saэgiste ja protsessi selektiivsuse kohta.

\section{N. $Z L O B I N$}

\section{DIE DEHYDROGENISATION VON $n$-OKTAN AN PLATINKATALYSATOREN}

Der Beitrag bringt die Ergebnisse einer Dehydrogenisation von n-Oktan an $\mathrm{Pt} / \mathrm{Al}_{2} \mathrm{O}_{3}$ mit Hilfe der Reaktionsgaschromatographie. Als Trägergas wird Helium benutzt.

Es wird die Einwirkung der Pt-Menge, der Kontaktschichtlänge und der Reaktionstemperatur auf die Ausbeute von $n$-Oktenen und auf die Selektivität gezeigt. 